peritoneal granulomas including infections (tuberculosis, fungal infections and parasitic infestations), foreign material (starch, douche fluid, lubricants, fibres from surgical material, escaped bowel contents, leaked bile, ruptured ovarian cysts, and so on), and conditions such as Crohn's disease, sarcoidosis and Whipple's disease. ${ }^{1}$ However, as far as we are aware, a granulomatous response to escaped gallstones has not been reported, partly because gallstone spillage during traditional open cholecystectomy is uncommon and, if it does occur, retrieval of stones is relatively straightforward. With the widespread use of laparoscopic cholecystectomy nowadays, foreign body granulomas due to gallstones are likely to present, albeit incidentally, to pathologists more frequently, either as surgical biopsy material or at necropsy. Thus one more cause of intraperitoneal granulomas needs to be added to the traditional list.

The authors wish to thank Mr Sadek, St James's University Hospital, Leeds, for his kind permission to report this case.

1 Clement PB. Diseases of the peritoneum. In: Kurman RJ, ed. Blaustein's pathology of the female genital tract. 4 th edn New York: Springer-Verlag, 1994:647-703.

2 Sadler GP, Shandall A, Rees BI. Laparoscopic cholecystectomy. Br f Hosp Med 1992;48:462-71.

3 Strasberg SM, Soper NJ. Laparoscopic cholecystectomy. Curr Opin Gastroenterol 1993;9:829-34.

4 Deziel DJ, Millikan KW, Economou SG, Doolas A, Ko SDeziel DJ, Millikan KW, Economou SG, Doolas A, Ko S-
T, Airan MC. Complications of laparoscopic choleT, Airan MC. Complications of laparoscopic cholecystectomy: a national survey of 4,292 hospitals and
analysis of 77,604 cases. $A m \mathcal{F}$ Surg 1993;165:9-14.

5 Crist DW, Gadacz TR. Complications of laparoscopic surgery. Surg Clin North Am 1993;73:265-89.

6 Lee VS, Paulson EK, Libby E, Flannery JE, Meyers WC Cholelithoptysis and cholelithorrhea: rare complications of laparoscopic cholecystectomy. Gastroenterology 1993;105: 1877-81.

7 Ponsky JL. The incidence and management of complications of laparoscopic cholecystectomy. Adv Surg 1994;27:21-41.

\title{
Ulcerating rheumatoid nodule of the vulva
}

\author{
M A C Appleton, S M Ismail
}

\begin{abstract}
A case of an ulcerating rheumatoid nodule of the vulva in a 76 year old woman with rheumatoid arthritis complicated by Felty's syndrome is reported. The patient presented with a mass in the vulval region. On clinical examination, she had an ulcerated mass associated with inguinal lymphadenopathy. These findings resulted in a clinical diagnosis of invasive carcinoma of the vulva and an excision biopsy was carried out. On microscopic examination, the lesion showed the characteristic features of a rheumatoid nodule with ulceration of overlying epidermis. Adjacent vessels showed inflammation and fibrinoid necrosis of their walls suggestive of a vasculitis. Awareness of the possibility of ulceration in rheumatoid nodules may facilitate diagnosis and avert unduly aggressive treatment.
\end{abstract}

(f Clin Pathol 1996;49:85-87)

Keywords: rheumatoid arthritis, rheumatoid nodule, vulva, vasculitis.

Rheumatoid nodules occur in approximately $25 \%$ of patients with rheumatoid arthritis. They are usually found in subcutaneous tissue near a joint, but may also occur at other sites, including the heart, lung, gastrointestinal tract, and synovial membrane. ${ }^{1}$ Histologically, they are characterised by central fibrinoid necrosis surrounded by palisading histiocytes.

Here, we report a case of a rheumatoid nodule in the vulva of a woman with seropositive rheumatoid arthritis and Felty's syndrome. To our knowledge, this is the first report in the literature of a rheumatoid nodule at this site. Additional unusual features in this case included ulceration of the overlying skin and associated lymphadenopathy, resulting in clinical mimicry of carcinoma.

\section{Case report}

A 76 year old woman with a 40 year history of rheumatoid arthritis complicated by Felty's syndrome presented with a painful swelling on the vulva. The initial clinical suspicion was of infection and antibiotic therapy was instituted. There was no resolution and over the course of the next three months the lesion enlarged. Physical examination showed a left labial mass measuring $3 \times 4 \mathrm{~cm}$ with a $1.5 \mathrm{~cm}$ overlying ulcer with a raised rolled edge. There was induration of surrounding tissues and inguinal lymphadenopathy was present. The clinical diagnosis at this stage was one of invasive carcinoma and an excision biopsy of the mass was carried out.

Apart from Felty's syndrome (rheumatoid arthritis associated with splenomegaly, lymphadenopathy and neutropenia), there was no past medical history of note. No rheumatoid nodules were noted on extensor surfaces. There was no history of previous gynaecological neoplasia or surgery. There was no history of diabetes mellitus. The patient was taking $7.5 \mathrm{mg}$ of prednisolone daily.

\section{PATHOLOGY}

Macroscopic features

The resection specimen consisted of an oval of hair bearing skin measuring $4.3 \times 3.0 \mathrm{~cm}$ with 


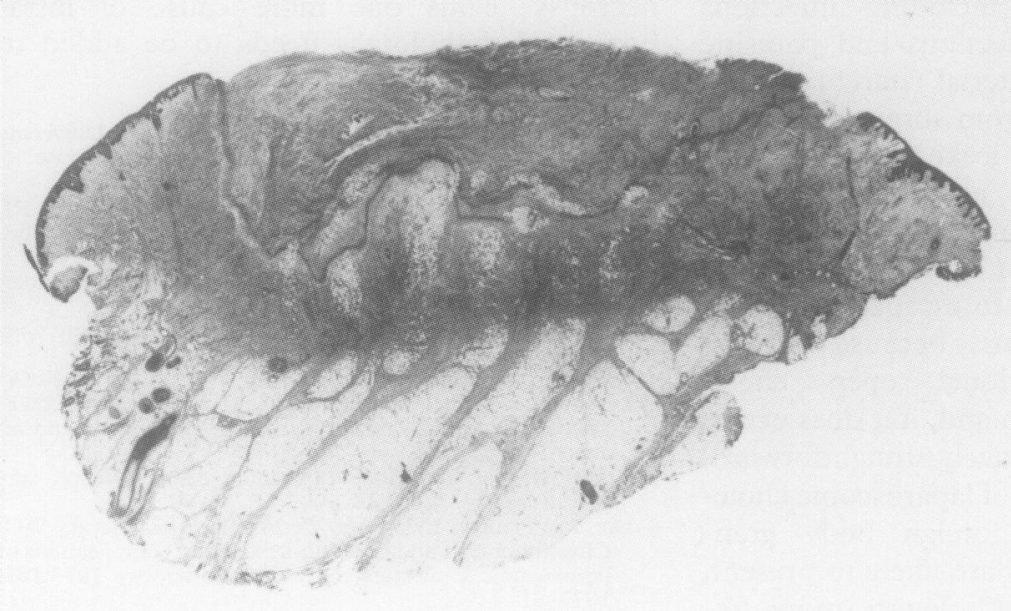

Figure 1 Low power, whole mount section of the specimen showing ulceration and central necrosis.

underlying subcutaneous tissue to a depth of $1 \cdot 0 \mathrm{~cm}$. An irregular ulcer measuring $2 \cdot 2 \times$ $1.7 \mathrm{~cm}$ was present on the skin surface.

\section{Microscopic features}

Histological examination revealed epidermal ulceration with a large lesion occupying the dermis and extending into subcutaneous fat (fig 1). A central necrotic core contained the preserved outlines of adipocytes and blood vessels. Surrounding this was a zone of palisading histiocytes (fig 2), which showed prominent foci of leucocytoclasis and also occasional multinucleated giant cells, including some of Touton type. Deep to this were zones of myxoid connective tissue, vascular granulation tissue and fibrosis. Vessels surrounding the necrotic

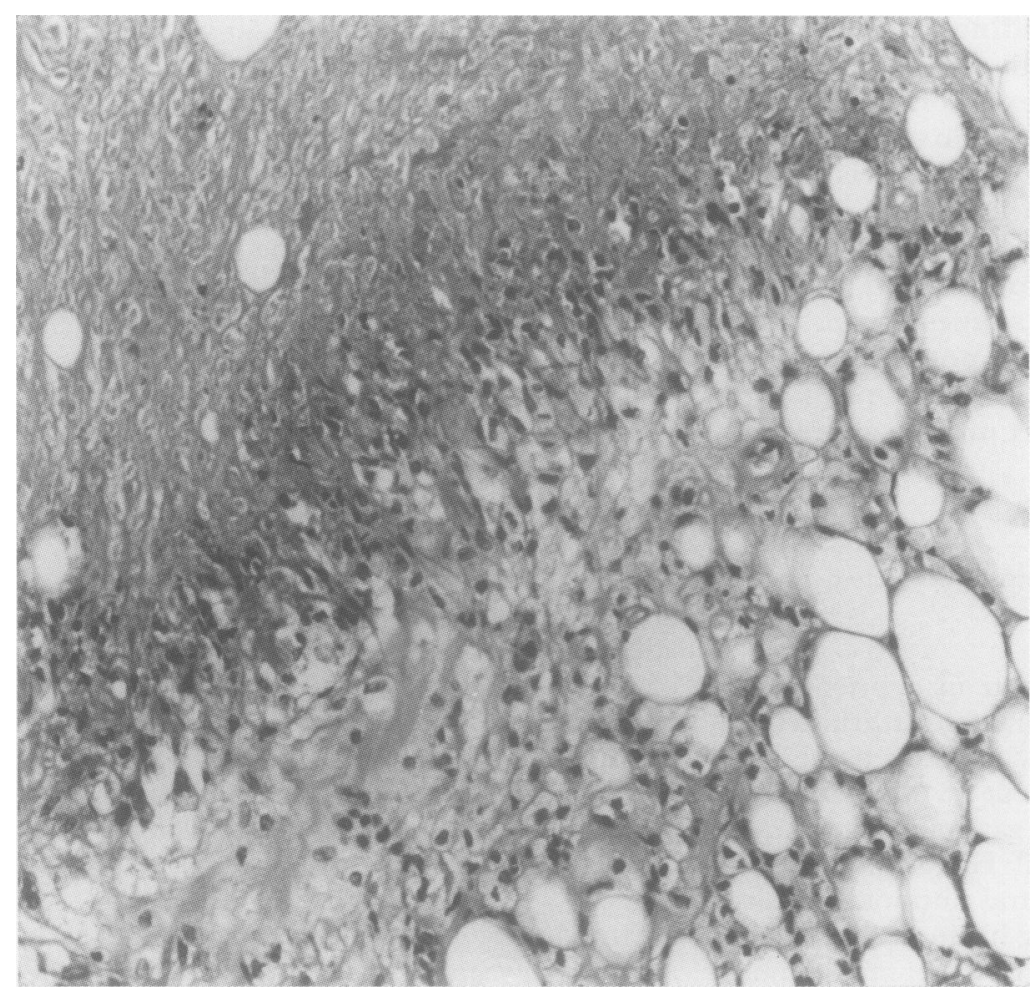

Figure 2. The periphery of the lesion shows necrobiosis with surrounding palisading histiocytes and leucocytoclasis. (Haematoxylin and eosin, $\times 200$.) core showed endarteritis obliterans. Some vessels also showed fibrinoid necrosis of their walls with an associated inflammatory cell infiltrate, indicating a vasculitis. Stains for organisms, including acid fast bacilli and fungi, were negative. No polarisable foreign material was evident. The epidermis adjacent to the ulcer showed hyperplasia but no evidence of dysplasia.

\section{Discussion}

Rheumatoid arthritis is a systemic disorder which characteristically causes inflammatory synovitis with an erosive arthritis, but has manifestations in numerous other organs and systems. Common extra-articular manifestations include rheumatoid nodules and acute vasculitis. These are seen in patients with high serum rheumatoid factor titres and are associated with more severe and progressive disease.

Subcutaneous rheumatoid nodules may be single or multiple and classically occur over the extensor surfaces of joints, the usual site being the elbow. Size varies from a few millimetres to $2 \mathrm{~cm}$, although they may be larger.

Ulceration of the overlying skin is a rare event in subcutaneous rheumatoid nodules, with only 17 cases previously reported in the literature. The terms superficial ulcerating rheumatoid necrobiosis ${ }^{2}$ and perforating rheumatoid nodule ${ }^{3}$ have been applied to ulcerated rheumatoid nodules. The examples reported to date have had a typical periarticular location in either superficial or deep dermis or subcutis. The present case is unusual not only in its location in the labium majus but also in its lack of proximity to a joint.

The pathogenesis of rheumatoid nodules is poorly understood, but local trauma ${ }^{4}$ and vasculitis ${ }^{5}$ have been implicated in this process. The presence of vasculitis in the present case and a case of superficial ulcerating rheumatoid necrobiosis ${ }^{2}$ indicates that it may have a role in the development of these lesions.

Necrobiotic granulomas with similar histological features to rheumatoid nodules have been reported in the female genital system, although not in the vulva. These invariably occurred in patients without rheumatoid arthritis and followed surgical procedures, including diathermy tubal ligation, ${ }^{6}$ laser endometrial ablation, ${ }^{7}$ endometrial curettage, ${ }^{8}$ cervical biopsy, ${ }^{8}$ and partial ovarian resection. ${ }^{9}$ There was no history of previous vulval surgery in the case presented here.

The histological differential diagnosis also includes necrobiosis lipoidica and granuloma annulare. ${ }^{1}$ The former typically occurs on the shin and is associated with diabetes mellitus. The latter may be difficult to distinguish from a rheumatoid nodule on histological grounds alone, but the history of seropositive rheumatoid arthritis can be considered diagnostic of rheumatoid nodule in the present context.

This case illustrates the occurrence of a relatively common lesion at a previously unreported site. The presence of overlying ulceration, a rare feature, together with lymph- 
adenopathy in this woman with Felty's syndrome resulted in an initial diagnosis of carcinoma. Awareness of this rare presentation may aid earlier diagnosis and prevent undue treatment for carcinoma.

We thank Mrs S M Walker for allowing us to report this case.

1 Bullough PG. Rheumatoid arthritis. In: Sternberg SS, ed. Diagnostic surgical pathology. 2nd edn. New York: Raven Press, 1994:235-6.

2 Patterson JW, Demos PT. Superficial ulcerating rheumatoid necrobiosis: a perforating rheumatoid nodule. Cutis 1985 ; 36:323-8.
3 Horn RT, Goette DK. Perforating rheumatoid nodule. Arch Dermatol 1982;118:696-7.

Ziff M. The rheumatoid nodule. Arthritis Rheum 1990;33: 761-7.

5 Sokoloff L, McCluskey RT, Bunim JJ. Vascularity of the early subcutaneous nodule of rheumatoid arthritis. Arch Pathol subcutaneous nodu

6 Roberts JT, Roberts GT, Maudsley RF. Indolent granulomatous necrosis in patients with previous tubal diathermy Am $\mathcal{F}$ Obstet Gynecol 1977;129:112-13.

7 Akosa AB, Boret F. Necrotising granulomas of the uterine corpus. F Clin Pathol 1993;46:953-5.

8 Evans CS, Klein HZ, Goldman RL, Kohout ND. Necrobiotic granulomas of the uterine cervix. Am $\mathcal{F}$ Surg Pathol 1984; 8:841-4.

9 Herbold DR, Frable WJ, Kraus FT. Isolated noninfectious granulomas of the ovary. Int $\mathcal{f}$ Gynecol Pathol 1984;2: 380-91.

\title{
Pleomorphic adenoma of the bronchus
}

\author{
E C Sweeney, M McDermott
}

\begin{abstract}
An example of pleomorphic adenoma of the bronchus is described in a 27 year old male student who was referred for evaluation of a coin lesion identified incidentally on chest $x$ ray. The tumour exhibited the classic histological, immunohistochemical and ultrastructural features of this rare entity but, in addition, contained mature and immature adipose tissue in the stroma and showed transition, in its superficial portion, between ostensibly normal bronchial mucus glands and tumour tubules. Neither of these features has been commented upon previously. (f Clin Pathol 1996;49:87-89)
\end{abstract}

Keywords: bronchus, pleomorphic adenoma, adipose tissue, mucus glands.

\section{Case report}

A 27 year old male student was referred for evaluation of a coin lesion identified incidentally on chest $x$ ray. An $x$ ray taken four years earlier for an insurance examination had been reported as normal. The patient had no symptoms and no past medical history. He had smoked 20 cigarettes daily up to four months before presentation. Physical examination and routine laboratory tests were normal.

Computed tomography examination revealed a $3 \mathrm{~cm}$ enhancing mass, with well defined margins, at the hilum of the right lung. On endoscopy, a polypoid tumour was seen in the lower lobe bronchus, but biopsy specimens of the surface of this were not diagnostic. A lower lobectomy was performed. On gross examination, there was a well circumscribed $3.5 \mathrm{~cm}$ grey-yellow tumour, largely located within pulmonary parenchyma but projecting intraluminally through the wall of the bronchus, $2 \mathrm{~cm}$ from the bronchial resection margin.

\section{Methods}

Tissue blocks were fixed in $10 \%$ buffered formalin, routinely processed and embedded in paraffin wax. Sections were stained with haematoxylin and eosin, alcian blue $(\mathrm{pH} 2.5)$ and periodic acid Schiff (PAS) after diastase pretreatment. Sequential sections were stained for keratin (AE1/AE3; ICN, Costa Mesa, California, USA), S100 protein and epithelial membrane antigen (EMA) (Dako, Glostrup, Denmark) and smooth muscle actin (Enzo Diagnostics, New York, USA). Further tissue blocks were fixed in 3\% glutaraldehyde and examined by electron microscopy.

\section{MICROSCOPY}

On its bronchial aspect, the lesion was covered by normal respiratory epithelium. Within the lung, however, it was separated from normal parenchyma by a dense fibrous capsule of variable thickness. Peribronchial adipose tissue was present at the resection margin of the lobectomy specimen but not in the immediate vicinity of the tumour. The mass was roughly spherical and, at its centre, had a stellate, parvicellular area, radiating from which were irregular, solid islands of polygonal epithelial cells with moderate amounts of eosinophilic cytoplasm, and scattered cells, either singly or in groups, in which the cytoplasm had a more hyaline, glassy appearance. The stroma between the cellular areas contained spindle shaped and stellate cells set in a variably myxoid, hyaline or focally chondroid matrix. Zones of adipose tissue were easily identifiable in the stroma (figure, panel A), some of which contained lipoblasts (figure, panel B). In both the cellular and myxoid areas there were well formed tubular structures, many of which were lined by distinct epithelial and myoepithelial layers. Squamous metaplasia was identified in 